\title{
Mining
}

\section{Circulating load calculation in grinding circuits}

\section{Cálculo da carga circulante em circuitos de}

\section{moagem}

\begin{abstract}
André Carlos Silva
Professor Adjunto II do Departamento de Engenharia de Minas da Universidade Federal de Goiás, Campus Catalão.

andre@iceb.ufop.br

\section{Elenice Maria Schons Silva \\ Professora Assistente II da Universidade Federal de Goiás e Subcoordenadora do Curso de Especialização em Tratamento de Minérios. elenice@catalao.ufg.br}

Ricardo Antonio de Rezende

Universidade Federal de Goiás (UFG)

ricardo_07_9@hotmail.com

\begin{abstract}
A problem for solving mass balances in mineral processing plants is the calculation of circulating load in closed circuits. A family of possible methods for the resolution of these calculations is the iterative method, consisting of a finite loop where in each iteration the initial solution is refined in order to approach the exact solution. The present work presents a low-complexity iterative algorithm for circulating load calculation in mineral processing closed circuits, thus enabling the construction of reliable mass, metallurgical and water balances. The proposed equations on the algorithm were obtained through the analysis of many industrial systems, taking into account the process operational parameters. A validation was performed with real industrial data, in order to ensure a greater reliability of the obtained results. Two different types of closed circuits are presented, each one with different levels of complexity, to clarify the proposed algorithm. With the results, it is possible to affirm that the proposed iterative algorithm can be successfully applied to any kind of closed circuit in mineral processing. The results were satisfactory with respect to processing speed, convergence of the solution and the number of iterations required for the circulating load calculation.
\end{abstract}

Keywords: mass balance; circulating load; closed circuits.

\section{Resumo}

Um problema para a resolução de balanços de massa, em usinas de processamento mineral, é o cálculo da carga circulante presente em circuitos fechados. Uma família de métodos possíveis de aplicação, para a resolução desse cálculo, diz respeito aos métodos iterativos, que consistem em um loop finito, no qual a cada iteração a solução inicial do sistema é refinada de modo a se aproximar da solução real. O presente trabalho apresenta um algoritmo iterativo de baixa complexidade, para o cálculo de carga circulante em circuitos fechados, possibilitando, assim, a construção de balanços de massa, metalúrgico e de água que seja confiável. As equações propostas, no algoritmo, foram obtidas através da análise de diversos sistemas industriais, levando-se em conta os parâmetros operacionais do processo. A validação do método foi realizada com dados industriais reais, visando a assegurar uma maior confiabilidade dos resultados obtidos. Dois diferentes tipos de circuitos fechados, com diferentes níveis de complexidade, são apresentados de modo a elucidar o algoritmo proposto, permitindo-se afirmar que tal algoritmo pode ser aplicado a qualquer circuito fechado, no processamento de minerais. Os resultados obtidos foram satisfatórios, no que tange à velocidade de processamento, à convergência da solução e ao número de iterações necessárias para o cálculo da carga circulante.

Palavras-chave: balanço de massas; carga circulante; circuitos fechados. 


\section{Introduction}

The mass balances in mineral pro-

cessing circuits are based on the equation

$$
\mathrm{F}=\mathrm{C}+\mathrm{T}
$$

Where $\mathrm{F}$ is the flow (mass or volume) entering the system; $\mathrm{C}$ is the flow (mass or volume) of concentrate and $\mathrm{T}$ is the flow (mass or volume) both coming out of the system.

Equation 1 assumes theoretical conditions for streaming the operation, whose fundamental assumption is that the mass that enters the system is equal to the mass that comes out of the system (Lavoisier's law of mass conservation). Data obtained in technological characterization tests or through sampling campaigns in mineral processing plants must be consistent and reliable, being common the reconciliation of experimental data using simulation software. Thus, the mass balance of the circuit is used to confirm the quality of the data and the use of computational simulation aims to extend the knowledge of the industrial process's function being, also, a tool for further studies of process optimization.

The circulating load can be defined as a process flow (mass or volumetric) of a given material that returns to a unit operation after failing to fulfill some selection criteria. The overall circulating load is usually build up due to true classification and equipment inefficien- of mass conservation, given by:

cies. In order to develop correlations of these effects, performance curves are a more logical approach that can express the relationship between both processes true classification and inefficiencies. In general, when the material does not meet the upstream specifications it will tend to move to the classifier underflow stream. In closed circuit grinding, as the example depicted in figure 1 , the circulating load is, in some cases, 400 times the ratio of the weight of the hydrocyclone oversize returning to the reduction machine to the weight of new feed entering the circuit in the same time interval.

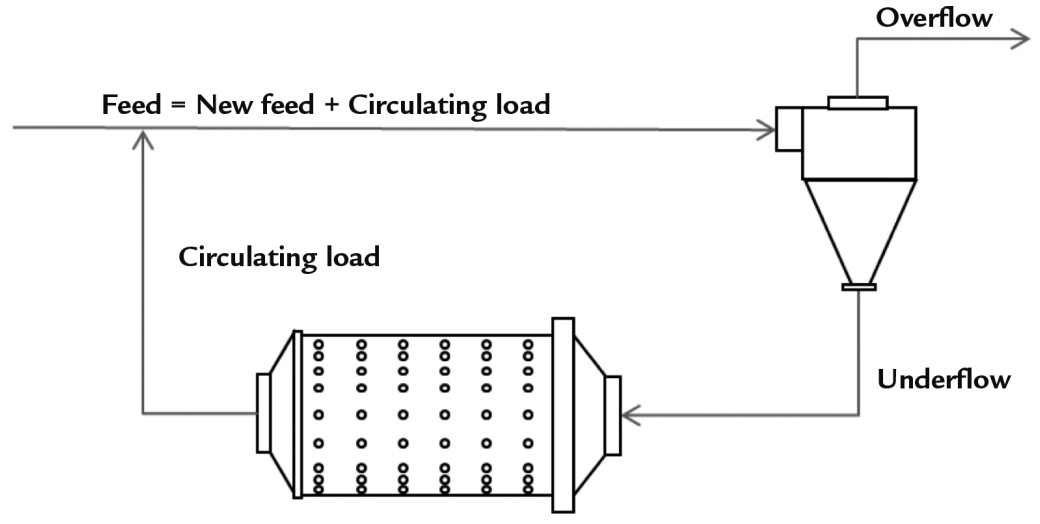

For better understanding of the overall circuit operation the correct prediction of a circuit circulating load is essential for obtaining the most reliable mass balance (response when simulations needs to be performed. Chen et al. (2008), working with predictive control models applied to ball mills stated, that the stable control of the grinding process has a great importance in achieving improvements in equipment operation efficiency, for the valuable mineral recovery and significant cost reductions. Lestage et al. (2002) presented a supervisory system for realtime milling circuits optimization, where the circulating load was one of the most important configuration parameters of the system and its value was dependent of operational parameters such as feed rate, pulp density and particle size distribution of the feed and product.

White et al. (1977) studied algorithms used for data reconciliation from field measurements with the mass balance results. According to the authors, a simple algorithm based in the least squares method could be applied to minimize errors and should be adequate to adjust the real to the theoretical data. The grinding circuit data had to be reconciled, due to the lack of an effective procedure for calculating with good accuracy the circulating load of these circuits.

Complex circuit analysis with reductant data in mineral processing historically requires a wide sampling
Figure 1

Grinding circuit closed by a hydrocyclone.

campaign and the use of matrix models for each mineral component in each sampled flow. Wills (1986) demonstrated how complex circuits can be solved by transforming the productive flowchart in a graph, where each node represents a unit operation.

The present work presents a low complexity algorithm with high convergence speed for circulating load calculation in mineral processing closed circuits. The obtained results indicate that the proposed algorithm can be satisfactorily used for circulating load calculation in any closed circuit, regardless of the complexity of the circuit, with low computational demand and high convergence speed of the result.

\section{MATERIAL AND METHOD}

\subsection{Algorithm's general formulation}


variations of operating parameters, such as grades, partitions and metallurgical recovery. From these observations, a correlation between all kinds of circuits was

Wherefiis the flow (volumetric or mass) which feeds the i-th unit, an operational unit that contributes directly to the circulating load and $\mathrm{pi}$ is the flow partition in the same unit operation, calculated according to the unit's operation and its operational parameters. The product pi.fi is nothing more than the output stream of the i-th unit operation that contributes directly to the circulating load.

The circulating load calculation shown in equation 2 differs from that proposed by Tsakalakis (2000) by combining the unit's operational efficiencies in a single parameter (pi). The exact result obtained by the author with the use of a monograph can also be obtained by using equation 2, eliminating the need of this chart.

The linearity hypothesis proposed by Meloy (1983) was considered for developing the iterative algorithm proposed. The linearity hypothesis method assumes that in a separation process, there is no particle-particle interactions that may affect the probability of a particle being selected for an output stream. In other words, this hypothesis indicates that established, regardless of the circuit's complexity level. Yingling (1990) used a Markov chain to model the mineral flow in mining operations. From this work, the concep-

$$
C L=\sum_{i=1}^{n}\left(p_{i} \cdot f_{i}\right)
$$

if the feed flow of a given unit operation is doubled or tripled, the fraction of particles possessing a given selection feature will continue the same in each of the unit's operational output stream. However, this hypothesis is not real, since an increase in the feed flow will affect the behavior of the operation itself, separation or classification. The adoption of the linearity hypothesis proposed by Meloy (1983) simplifies the proposed algorithm, since the unit's operational partition varies linearly with the operation's feed. However, any other model that allows the calculation of the unit's operational feed partition can be adopted without any change in the proposed algorithm. Jankovic and Valery (2013) correlated the grinding and classification efficiency with the circulating load in closed circuit grinding operations. The same authors also showed that the hydrocyclone's classification efficiency does not vary linearly with the circulating load in this circuit type.

The computed error usually arises from the difference between the circulating load calculated in the k-th and in the (k-1)-th itera- tion of an iterative method for the calculation of the circulating load was achieved. At each iteration, the circulating load CL is calculated using the following equation:

tions. The error in the first iteration is set as the circulating load computed in this iteration. At the beginning of every the iteration, the feed of each unit operation must be computed because it depends on the circulating load and on the flow split.

Figure 2 presents the proposed iterative algorithm for the closed circuit circulating load computation. It can be noted that the iterations are repeated until the preset tolerance limit is reached. The reason is that the solution obtained by this method is not exact. It is only an approximation of the real solution. The convergence of the method is provided by calculating the error, which can be both positive and negative. The Meloy (1983) linearity hypothesis applies here, since at every iteration, the feed circuit varies, keeping constant the partition of each unit operation involved.

It stands out that the flow of water in a given circuit can be calculated using the proposed algorithm without any additional modification. In this way, the feed flow (fi) to be used in the algorithm can be a solid, water or pulp flow.
Figure 2

Iterative algorithm for circulating load calculation in closed circuits.

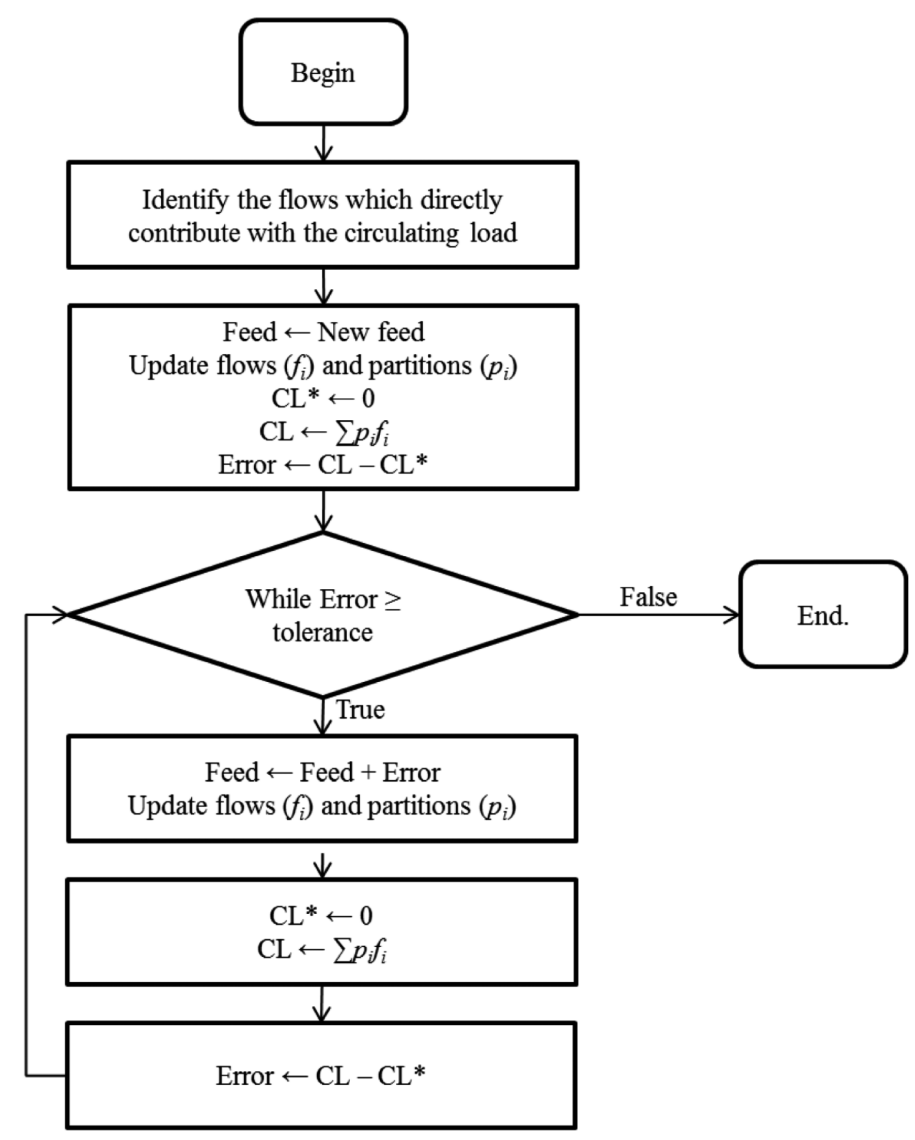




\subsection{Application of proposed method for grinding circuits}

For analysis and validation of the proposed iterative algorithm, four circuits with different levels of complexity were tested. All analyzed circuits were built based on actual industrial processes present in mining companies installed in Catalão/GO/Brazil, in order to be able to compare the results ob- tained by the proposed algorithm with the data provided by the companies. The first considered circuit is a simple closed-circuit grinding, as shown in figure 1, which is used as a secondary ball mill by VALE Fertilizers Company, Catalão/GO, Brazil. According to Furuya et al. (1971) closed-circuit com-

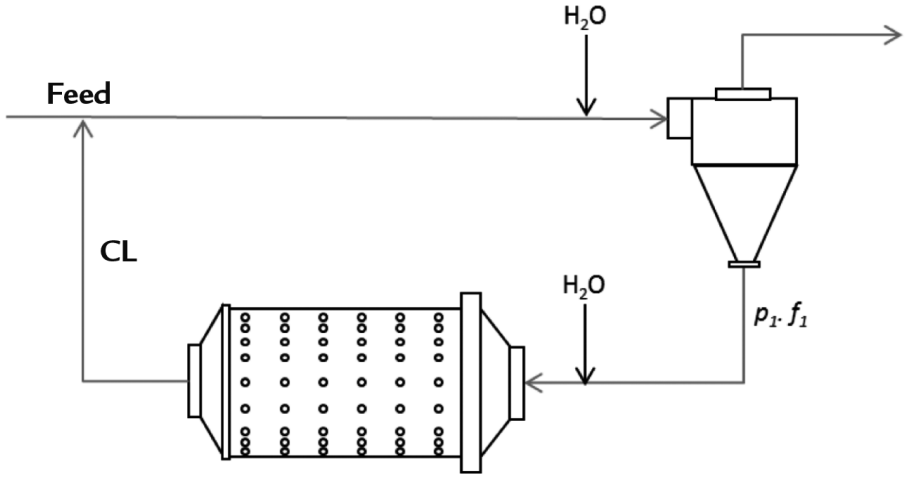

The circuit shown in figure 4 is used as secondary ball mill in AngloAmerican Phosphate, Catalão/GO, Brazil and it is a grinding circuit where a low-field magnetic separator receives part of the hydrocyclone underflow. The flow parti- tion is physically made by valves installed in the pipeline. The addition of a magnetic separator in the circuit changes the circulating load calculation, because it was generated another output flow and two other partitions. The circulating

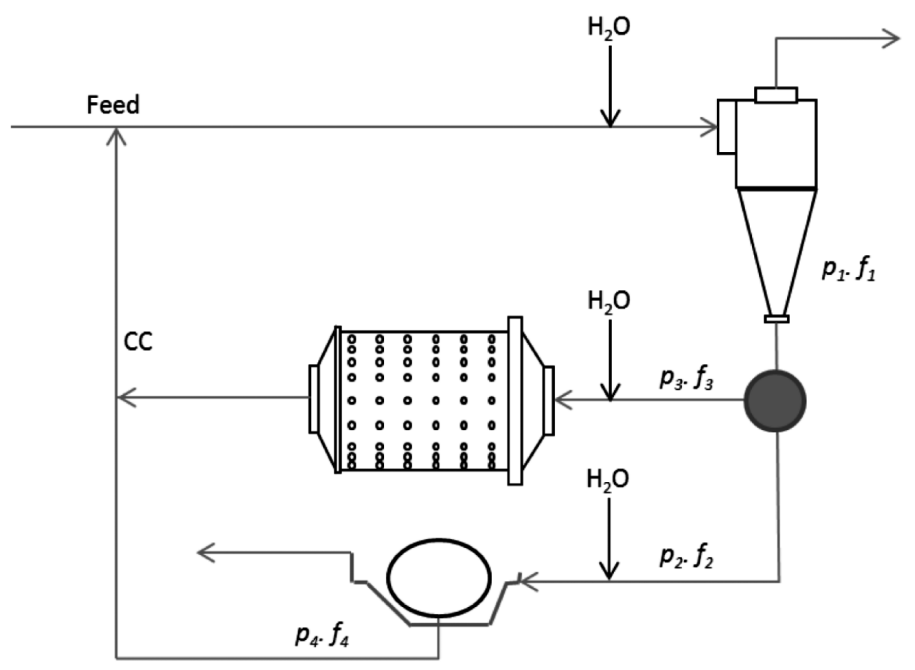

\section{Results and discussion}

Table 1 summarizes the results of the proposed iterative method applied to simple grinding (figure 3 ). The adopted hydrocyclone flow split parameter was $83.74 \%$. This indicates that $83.74 \%$ of the hydrocyclone feed returns to the mill as circulating load. Considering the new feed is equal to $482 \mathrm{t} / \mathrm{h}$, the calculated circulating load was equal to $2,482.33 \mathrm{t} / \mathrm{h}$, being neces- minution systems typically involve mills, classifiers and material transport equipment in various combinations, being the combination presented in figure 1 the most common. The coarse particles are separated by a classifier (in this case a hydrocyclone) and fed back into the mill.

Figure 3

A simple grinding closed circuit.

load calculation in this case will take into account the hydrocyclone partition, the pipeline partition and the magnetic separator partition. This circuit is used industrially for separation of magnetite present in phosphate ore.

Figure 4

Closed circuit grinding with a low-field magnetic separation.

sary 177 iterations for the calculation. The time spent in a Samsung notebook RV411 Intel i3 processor $2.53 \mathrm{GHz}$, 3.0 GB RAM operating in Windows 7 system was 3.01 seconds. 
Table 1

Results of the iterative algorithm applied to the figure 3 milling circuit.

For the grinding circuit described in figure 4 also composed with the lowfield magnetic separator, the adopted hydrocyclone flow split parameter $(\mathrm{p} 1)$

Table 2

Results of the iterative algorithm applied to figure 4 representing the milling circuit.

It is worthwhile mentioning that in each iteration the computed value obtained for the circulating load changes until the convergence criteria is reached. This is due to the fact that the method iterates the value of the feed to the circuit while the error converges to zero. Therefore, the

\section{Conclusions}

The proposed iterative algorithm was valid and acceptable in relation to the iteration number and convergence speed for different circuit types and complexities. It is noticed that the iterative method converges faster to the exact solution in the second example than in the first one. This fact can be proven by examining the itera-

\begin{tabular}{c|c}
\hline New feed & $482 \mathrm{t} / \mathrm{h}$ \\
\hline Hydrocyclone partition $\left(\boldsymbol{p}_{1}\right)$ & $83.74 \%$ \\
\hline Physical partition $(\mathrm{p} 2)$ & $5.0 \%$ \\
\hline Circulating load & $2,482.33 \mathrm{t} / \mathrm{h}$ \\
\hline Hydrocyclone overflow & $515 \%$ \\
\hline Iterations & $482 \mathrm{t} / \mathrm{h}$ \\
\hline Time spent & 177 \\
\hline
\end{tabular}

was equal to $76.29 \%$ and the flow split for the low-field magnetic separator parameter (p2) was equal to $15 \%$. Considering that the new feed is equal to $303.74 \mathrm{t} / \mathrm{h}$, the computed circulating load was $947.14 \mathrm{t} / \mathrm{h}$, requiring 118 iterations $(2.72 \mathrm{~s})$. Those results are presented in table 2 .

\begin{tabular}{c|c}
\hline New feed & $303.74 \mathrm{t} / \mathrm{h}$ \\
\hline Hydrocyclone partition $\left(\boldsymbol{p}_{1}\right)$ & $76.29 \%$ \\
\hline Low-Field magnetic separator partition $(\mathrm{p} 4)$ & $85.00 \%$ \\
\hline Circulating load & $947.14 \mathrm{t} / \mathrm{h}$ \\
\hline Hydrocyclone overflow & $311.82 \%$ \\
\hline Low-field magnetic separator concentrate & $296.58 \mathrm{t} / \mathrm{h}$ \\
\hline Iterations & $7.16 \mathrm{t} / \mathrm{h}$ \\
\hline Time spent & 118 \\
\hline Error & $2.72 \mathrm{~s}$ \\
\hline
\end{tabular}

smaller the circulating load, the closer the solution is to the initially adopted value, and as such, fewer iterations will be necessary. In a computational sequence like that, the first approximation or the solution of the first iteration is called seed. The proposed method is analogous to the bisector method for algebraic root determination. In this method, the number of iterations depends on the amplitude between the two extreme points of the considered range. In the proposed algorithm, the number of iterations depends on the amplitude between the initial seed and the final solution. tion number needed for each circuit, being the cause of such behavior the fact that the initial solutions (the algorithm seed) in the second example were closer to the exact solution. For all circuits studied, the results were compared with the results obtained by Caspeo BILCOTM software, version 3.0, and similar results between the software and the proposed algorithm were found.

The present work shows that the calculation of the circulating load can be understood as a mathematical function where it is desired to minimize the error and, therefore, any error minimization techniques or mathematical optimization can be successfully used to calculate the circulating load. 


\section{Acknowledges}

The authors thank financial sup- port from the Brazilian agencies CNPq, CAPES, FAPEG and FUNAPE.

\section{References}

CHEN, X., LI, Q., FEI, S. Constrained model predictive control in ball mill grinding process. Powder Technology, v. 186, n. 1, p. 31-39, 2008.

FURUYA, M., NAKAJIMA, Y., TANAKA, T. Theoretical analysis of closed-circuit grinding system based on comminution kinetics. Industrial \& Engineering Chemistry Process Design and Development, v. 10, n. 4, p. 449-456, 1971.

JANKOVIC, A., VALERY, W. Closed circuit ball mill - basics revisited. Minerals Engineering, v. 43-44, pa. 148-153, 2013.

LESTAGE, R., POMERLEAU, A., HODOUIN, D. Constrained real-time optimization of a grinding circuit using steady-state linear programming supervisory control. Powder Technology, v. 124, n. 3, p. 254-263, 2002.

MELOY, T. P. Analysis and optimization of mineral processing and coal-cleaning circuits - circuit analysis. International Journal of Mineral Processing, v. 10, n. 1, p. 61-80, 1983.

TSAKALAKIS, K. Use of a simplified method to calculate closed crushing circuits. Minerals Engineering, v. 13, n. 12, p. 1289-1299, 2000.

WHITE, J. W., WINSLOW, R. L., ROSSITER, G. J. A useful technique for metallurgical mass balances - applications in grinding. International Journal of Mineral Processing, v. 4, n. 1, p. 39-49, 1977.

WILLS, B. A. Complex circuit mass balancing - a simple, practical, sensitivity analysis method. International Journal of Mineral Processing, v. 16, n. 3-4, p. 245-262, 1986.

YINGLING, J. C. Circuit analysis: optimizing mineral processing flowsheet layouts and steady state control specifications. International Journal of Mineral Processing, v. 29, n. 3-4, p. 149-174, 1990.

Artigo recebido em 24 de abril 2013. Aprovado em 18 de dezembro de 2013. 